\title{
The Effect of Moisture Content on the Performance of Melkassa Multicrop Thresher in Some Cereal Crops
}

\author{
Dessye Belay ${ }^{1, ~ *, ~ M e l k a m u ~ F e t e n e ~}{ }^{2}$ \\ ${ }^{1}$ Ethiopin Institute of Agricultural Research, Fogera National Rice Research and Training Center, Bahir Dar, Ethiopia \\ ${ }^{2}$ Department of Agricultural Engineering, Adama Science and Technology University, Adama, Ethiopia
}

Email address:

Dessyebelay20@gmail.com (D. Belay)

${ }^{*}$ Corresponding author

\section{To cite this article:}

Dessye Belay, Melkamu Fetene. The Effect of Moisture Content on the Performance of Melkassa Multicrop Thresher in Some Cereal Crops. Bioprocess Engineering. Vol. 5, No. 1, 2021, pp. 1-10. doi: 10.11648/j.be.20210501.11

Received: December 29, 2020; Accepted: January 11, 2021; Published: March 9, 2021

\begin{abstract}
Cereal grains are growing in greater quantities worldwide than the other crops and supply more food energy to the humankind however, harvesting and threshing operation of such crops are affected by moisture content. Therefore, the main objective of this study was to evaluate the effect of moisture content on the threshing performance. Evaluation was carried out by measuring the initial moisture content and then by adding water to the crops, the desired moisture content was achieved. The dimension of the grains was determined. Completely randomized design (CRD) with three replications was used to determine the effect of threshing efficiency, threshing capacity, fuel consumption, breakage of grain, germination rate, percentage of unthreshed grain and blower loss at 14\%, 18\%, and 22\% moisture content for barley, wheat, and teff selected varieties. Statistical analysis was made by (SAS-8) software. The results indicated that, as the crop moisture content increase, the dimension of grain, sphericity of seed, angle of repose, thousand grain mass, fuel consumption, and coefficient of friction were also increased. Whereas, threshing capacity, and efficiency, cleaning efficiency, density, germination rate, and grain breakages were deceased. This study concluded that for low fuel consumption, low unthreshed grain and better threshing, the moisture content of the crops should be between $14 \%$ to $18 \%$.
\end{abstract}

Keywords: Fuel Consumption, Grain Damage, Moisture Content, Performance of Thresher

\section{Introduction}

Cereal crops were mostly grasses cultivated for their edible seeds (actually called a caryopsis). Those were grown in greater quantities worldwide than any other type of crop and provide more food energy to the human race than other crops. It provides essential nutrients and energy in the everyday human diet through direct human consumption and also through meat production since they comprise a major livestock feed [8]. Cereal grains such as tef, maize, barley, sorghum, millet, and wheat are the major sources of food in Ethiopia. They represent about $86 \%$ of the total yearly production of 6-7 million tons of grains [6]. Cereal production involves various processes, including sowing, weeding, pesticide application/spraying, harvesting, cleaning, and processing [15]. Cereal seeds can be used for sowing crop plants, energy production, or food production. Among many cereal crops such as tef, maize, barley, sorghum, millet, wheat, etc., only three cereal crops (tef, barley, and wheat) were selected based on area coverage in Ethiopia for this research to check whether the moisture content of the biomass affects the performance of the thresher machine or not.

Barley (Hordeum vulgare L.) is an ancient and important cereal grain crop. It ranks fifth among all crops in dry matter production in the world today. It was mainly cultivated and used for human food supply in the last century but nowadays it is significantly grown as animal feed, malt products, beer production, and human food [5]. Barley has been cultivated in Ethiopia as early as 3000 years B.C. This long history of cultivation and the large agro-ecological and cultural diversity in the country has resulted in a large number of landraces (farmers' varieties) and rich traditional practices. Barley culture is usually practiced with little or no external inputs, mainly in the higher altitudes or on steep slopes and 
eroded lands in Ethiopia. It was a major staple food grain in the highlands and used for making bread, porridge, soup, roasted grain, and alcoholic and non-alcoholic drinks such as beer and malts respectively. The straws were used for animal feed, thatched roofs, and bedding. The physical properties of barley grain, like those of other grains and seeds, are essential for the performance of the thresher and the analysis of the behavior of the product during agricultural process operations such as handling, planting, harvesting, threshing, cleaning, sorting, and processing. Principal axial dimensions of barley grain are useful in selecting sieve separators [15].

Wheat (Triticum spp) also the most important staple food crop both in developed and developing countries and contributes more calories and proteins to the world diet than any other cereal crops. It is considered a good source of protein, minerals, B-group vitamins, and other necessary food products [22]. Although, the environmental conditions were affect the nutritional composition of wheat grains with its essential coating of bran, vitamins, and minerals. It is a portion of excellent health-building food. Wheat flour was used to prepare bread, biscuits, confectionery (sweet) products, and dynamic wheat gluten/ seitan. It was also used as animal feed, ethanol production, brewing of wheat beer, cosmetics production, wheat protein in meat substitutes and to make wheat straw composites [12]. The physical properties of wheat grain, like those of other grains and seeds, are essential for determining the performances of thresher and the analysis of the behavior of the product during agricultural process operations such as handling, planting, harvesting, threshing, cleaning, and processing.

On the other hand, Tef (Eragrostis tef Zucc.) is the most staple food crop in Ethiopia. It has existed in Ethiopia since the recorded history of the country and some authors believed that the pre-Semitic inhabitants might have domesticated it in B.C. Tef was originated and has distributed/disseminated in Ethiopia. Ethiopian farmers grew tef for centuries because of its various advantages such as food sources for human and animal feed, energy sources, minerals, etc. It has existed before the introduction of other cereals such as maize, wheat, barley, and others [31]. It was the smallest grain in the world, ranging from $1-1.7 \mathrm{~mm}$ long and $0.6-1 \mathrm{~mm}$ diameter, with an 1000 average grain weight of $0.3-0.4$ grams and taking 150 grains to weigh as much as one grain of wheat [19]. Tef accounts for about two-thirds of the daily protein in the diet of the Ethiopian population. Its grain is mainly used for making Enjera, porridge, bread, feed for animals, etc. Tef has a high economic value as its grain can be kept for many years in practice at any kind of storage facility without being seriously damaged by common storage insect pests [4]. The other grains can be used for making Injera; however, tef alone is preferred. Physical characteristics of tef such as its moisture content, size, shape, etc., are very important to determine the performance of the thresher machine.

The ways of post-harvesting of such crops have been affected by different factors like moisture content, and size of the grain. Thus, factors were observed in the farm area.
Mostly, the moisture content of crops was seriously affected productivity in terms of losses of quality and quantity. The physical property of cereal crops including the moisture content, size, types of grain, and environmental factors like weather conditions are the most common properties to affect the performance of the thresher during threshing. Therefore, these-mentioned problems could be solved by determining the physical properties of cereal crops and their characteristics by adjusting the clearance between drum and concave and by using appropriate moisture contents to get high threshing capacity, threshing efficiency, cleaning efficiency, and minimize grain damage and fuel consumption. The moisture content of the biomass is the most common properties to affect the performance of the threshing machine. This was an important property to solve many problems associated with the performances of machines and the analysis of the behavior of the product during agricultural process operations such as handling, planting, harvesting, threshing, cleaning, sorting, and drying. During threshing, there is grain loss due to the factor of moisture content, grain damage, etc. This affects threshing efficiency, threshing capacity, cleaning efficiency, fuel consumption, and grain damages.

Moisture content is one of the most important factors affecting the quality of cereal grains production since the amount of dry matter of grain is inversely related to the moisture content of the grain [13]. The moisture content of the crop has its effect on the product quality i.e. when the moisture content of the grain is very high of the threshing efficiency becomes low due to the attachment of chaffs on the wall of concaves and drums, on the other hand, if the moisture content of the grain is very low there is less time requirement and has low fuel consumptions but, there is high grain breakage due to less resistance of impact and shear of grains and also, had shattering or spreading out of seeds from the grain outlets. Therefore, the optimum amount of moisture content is very crucial for obtaining good results both in the quality and quantity of products. It involves cutting the crop when the grain has reached the physiological mature stage (moisture usually between 20-30\%).

Therefore, this study concerns the determination of moisture level and reduction of thus factors mentioned above. This means reduce grain damage during threshing and increase productivity through using appropriate moisture content, adjustment of clearance between concave and drum (cylinder), and use of available speed (revolution per minute (rpm)) during threshing. Hence, the study concerns the effect of the physical property of cereal crops mainly the determinations of moisture contents before threshing and the effect of moisture contents on the performance of the machine. It also concerns the determinations of grain damage and fuel consumption of the thresher and concerns the reduction of brain damage during threshing.

The general objective of the study was to determine the effect of moisture content of cereal crops on the performance of Melkassa multi-crop thresher.

The specific objectives of the study were: 
1. To determine the moisture content of the crop before threshing for tef, wheat, and barley crops.

2. To determine fuel consumption of the machine at different moisture content for tef, wheat, and barley crops.

3. To determine grain breakage during threshing for tef, wheat, and barley crops.

\section{Material and Methods}

\subsection{The Area of Study}

The performance evaluation of the thresher machine has been done at Melkassa Agricultural Research Center (MARC). It is one of the federal research centers located in the Oromia regional state of Ethiopia. The research center is geographically located in the central valley of Ethiopia around $117 \mathrm{~km}$ east of Addis Ababa and $17 \mathrm{~km}$ southeast of Adama town. The altitude of MARC is $1550 \mathrm{~m}$ and lies between $8^{\circ} 24^{\prime} 0^{\prime \prime}$ to $8^{\circ} 30^{\prime} 12^{\prime \prime} \mathrm{N}, 39^{\circ} 21^{\prime} 0^{\prime \prime}$ to $39^{\circ} 35^{\prime} 14^{\prime \prime} \mathrm{E}$ latitude and longitude, respectively. Agro-ecologically, the area is characterized as arid and semi-arid with maximum and minimum temperatures are $28.40^{\circ} \mathrm{C}$ and $14.00^{\circ} \mathrm{C}$, respectively.

\subsection{Description of the Machine}

MARC has many types of threshers among them one constructed thresher was taken for this study. The thresher is a diesel engine motor-operated type for threshing of cereal crops known as a multi-crop thresher. The dimension of the machine is over-all height $1068 \mathrm{~mm}$, length at the drum position is $940 \mathrm{~mm}$ and drum length is $830 \mathrm{~mm}$, the width of the machine is $650 \mathrm{~mm}$, height up to the upper end of feeding rate is $1040 \mathrm{~mm}$. The dimension of the hopper is also width, length and height were $70 \mathrm{~mm}, 930 \mathrm{~mm}$, and $21 \mathrm{~mm}$ respectively, of the multi-crop thresher machine and the clearance between drum and concaves is $4 \mathrm{~mm}$. The diesel motor used for this thresher is the CF186FA model and 7.5hp $(5.6 \mathrm{KW})$ and having 3000rpm made in Korea. The selected thresher is comparatively small in size and has less weight. During threshing, the performance of the machine was evaluated by varying the moisture content of the crop. The feeding rate and speed of the engine (revolution per minute, rpm) were kept constant during testing. The performance of the machine could be evaluated to determine the threshing capacity, threshing efficiency, cleaning efficiency, fuel consumption, and grain breakage. The experiment has been replicated four replications at a different moisture content of the crop stalks, which means $14 \%, 18 \%$, and $22 \%$ dry base (d.b.) moisture content with the same or constant feeding rate and constant revolution per minute (rpm) of barley, wheat and tef grains.

\subsection{Performance Evaluation of the Machine}

The crop varieties that have been used in this study were one of the prevalent varieties were used for procured in farmers around Amhara Region Semen Shewa Zone of
Minjar Shenkora district. The samples were manually cleaned to remove unwanted materials from the crop stalks and then moisture by adding water on the samples to achieve the required amount of moisture contents that means, $(14 \%, 18 \%$, and $22 \%)$ through spreading of canvas on the ground and added water through sprayer by spraying. The initial moisture content of the crop stalks was measured by a moisture meter. After determining its initial moisture content, additional distilled water was added to the crops until it attains the required moisture content. Then started to thresh the crop with stalks and data was recorded. The recorded result includes threshing efficiency, cleaning efficiency, grain damage, threshing capacity, time taken, and fuel consumption. The initial moisture content was measured three times for getting of mean value by using a digital moisture meter (Draminski grain master, GM 667, Poland). The average initial moisture content was $13.73 \%$, $13.065 \%$, and $12.5 \%$ for barley, wheat, and tef crop with stalks respectively. Feed rate is the weight of total unthreshed grain fed into the thresher per unit of time. It was constant throughout the trials for determining the effect of moisture content on the performance of the thresher machine.

\subsubsection{Computation of the Performance Parameters}

\section{(i) Physical Properties of Grains}

The physical properties of wheat, barley, and tef grains, used during performance evaluation of the thresher machine, were identified and determined. The properties were the shape, shape factor (sphericity), bulk density, angle of friction, size, mass, bulk density, and static friction coefficient were measured and an average value was computed. The dimensions of seeds, in length, width, and thickness were measured in three directions by using a digital electronic caliper. Crops with initial damages such as scratches, abrasion, decay, and greening were not included in the sample.

\section{(ii) Size of Grains}

Fifty grains were randomly selected from the bulk of samples with three ranges of minimum, medium, and maximum sizes. Their three principal dimensions were measured using a digital Vanier caliper made in Taiwan that has an accuracy of $0.02 \mathrm{~mm}$. Athematic and geometric mean diameter; sphericity, surface area, bulk density, volume, and angle of repose of tubers were analyzed using standard procedures with three replications.

\section{(iii) Coefficient of Static Friction}

The coefficient of static friction $(\mu)$ on galvanized steel sheet, mild steel sheet, rubber, and timber sheet was measured for all crops by using the inclined plane method. The material was kept on a horizontally level surface and the slope was increased gradually. The angle $(\alpha)$ at impending slip was recorded and computed. The experiment was replicated three times and the mean value of the inclination angle was calculated. Then the coefficient of static friction $(\mu)$ 
was equal to $\tan \alpha$.

\subsubsection{Dependent Variables}

The performance of the machine could be evaluated through threshing capacity, threshing efficiency, cleaning efficiency, germination rate, fuel consumption, and grain loss. Data collection of dependent variables was applied through randomly selected three samples from each experimental unit. Variables examined and formulae used in computing the machine are stated as follows:

1. Threshing capacity: It is the weight of the threshed crop fed to the machine per unit of time. It can be defined as:

$$
T_{c}=\frac{M_{t}}{t}
$$

Where:

$\mathrm{M}_{\mathrm{t}}=$ Total mass of the crop biomass fed into the machine $\mathrm{t}=$ Total time is taken to thresh the crop.

2. Threshing efficiency (\%):

It also defined as,

$$
\eta_{t}=\frac{M_{t}-M_{u}}{M_{t}}
$$

Where:

$\mathrm{M}_{\mathrm{t}}=$ total mass of crop fed into the machine

$\mathrm{M}_{\mathrm{U}}=$ mass of unthreshed crop.

3. Cleaning efficiency: It is the ratio of the mass impurities to the total mass of grain at the machine main outlet expressed in percentage and is given as:

Where:

$$
\eta_{c}=\frac{M_{c}}{M_{t}}
$$

$\mathrm{M}_{\mathrm{C}}=$ the mass of cleaned grain at the machine main outlets

$\mathrm{M}_{\mathrm{t}}=$ the total mass of grain\& impurities at the main outlets

4. Percentage of loss $\left(\mathrm{P}_{\mathrm{L}}\right)$ : It is the ratio of the quantity of grain loss to the total quantity of the crop yield during threshing expressed as a percentage and is given as:

$$
P_{l}=\frac{M_{l}}{M_{t}} \times 100
$$

Where,

$\mathrm{P}_{\mathrm{L}}=$ the percentage loss $(\%)$

$\mathrm{M}_{\mathrm{t}}=$ the total mass of grain yield $(\mathrm{g})$

$\mathrm{M}_{\mathrm{l}}=$ mass of grain losses (unthreshed loss, separation loss, scattering, and loss blower loss) (g)

5. Germination rate $(\mathrm{G})$ : The germination test at a hundred (100) randomly selected seeds from each sample of the threshed crop was determined. The seeds were kept in a Petri dish lined with moist filter paper with distilled water in three replications and incubated at room temperature for eight days and then records the result in percent of the germinated to the total sample.

6. Fuel consumption $(\mathrm{Fc})$ : Before the start of each test trial, the fuel tank was filled to its capacity and after each test trial; the fuel consumed was measured by refilling the tank to the same level using a graduated cylinder. Mathematically can be calculated as [7].

$$
F_{c}=\frac{Q}{t}
$$

Where:

$\mathrm{Q}=$ Amount of fuel in $(\mathrm{L})$ consumed by the thresher $\mathrm{t}=$ Time taken in (hr.).

\subsection{Experimental Design}

Performance evaluation of the machine was through three levels of moisture contents: $\mathrm{mc}_{1}=14 \%, \mathrm{mc}_{2}=18 \%$ and $\mathrm{mc}_{3}=22 \%$ was used. The experimental design was a CRD 4 replicates giving 12 total experimental units [29]. The other parameters including feeding rate, the thresher drum RPM, concave clearance, and other crop parameters were kept constant. The experiment has been repeated four times for replication at a different moisture content of the crop biomass, $(14 \%, 18 \%$, and $22 \%)$.

\subsection{Data Analysis}

Data were subjected to analysis of variance using statistical Analysis System Software (SAS)-8 and Statistix-10 statistical soft wares [29]. When the effects of the treatments were found significant, the LSD test was performed to assess the difference between the treatments at a 5\% level of significance.

\section{Result and Discussion}

\subsection{Physical Properties of Cereal Crops}

Measurements made on some physical properties of cereal crops like barley (HB 42), wheat (Kakaba), and tef (Magna) varieties were measured in the experiment. Those are; moisture content, dimension (length, width, thickness), arithmetic, geometric, and equivalent mean diameter, sphericity, porosity, thousand-grain mass, density, surface area, coefficient of friction, and angle of repose.

\subsubsection{Dimensions of Grain}

The results of mean dimensions of barley and wheat seeds at different moisture content indicated that the size and dimensions of barley and wheat seed increased with increasing moisture content which validated previous results $[2,24]$. The moisture content was increased from 14 to $22 \%$, the length of barley and wheat seeds were increased from 9.87 to $11.13 \mathrm{~mm}$ and 5.98 to $6.86 \mathrm{~mm}$, the width of barley and wheat seeds were increased from 3.28 to $3.81 \mathrm{~mm}$ and 3.12 to $3.75 \mathrm{~mm}$ and also thickness of barley and wheat seeds were increased from 2.21 to $2.96 \mathrm{~mm}$ and 2.80 to $3.22 \mathrm{~mm}$ respectively. The arithmetic, geometric, and equivalent mean diameter of the three principal axis is also increased with the moisture content of barley, and wheat grains. There was an increase in the arithmetic, geometric, and equivalent mean diameter from 5.20 to $5.90 \mathrm{~mm}, 4.18$ to $5.09 \mathrm{~mm}$, and 4.23 to $5.05 \mathrm{~mm}$ for barley grains respectively, and 3.96 to $4.61 \mathrm{~mm}, 3.71$ to $4.34 \mathrm{~mm}$, and 3.72 to $4.37 \mathrm{~mm}$ for wheat grains respectively. It indicates that barley seeds can absorb more water and increase larger than wheat seeds. These are similar trends as obtained by African yam bean, barley, paddy, and Lablab seeds [9, 15, 23, 27]. 
The threshing cylinder-concave clearance is determined by the length, width, and thickness of each grain. If the clearance is large, there will be un-threshed grain pass away to the straws while small clearance may result in excessive breakage of grains due to crushing. Generally, the moisture content of the crop increased, the dimension of grains also increased. Therefore, the moisture content and dimension of barley and wheat seeds have directly related to each other. The area based on the arithmetic and geometric mean diameter was also increased with an increased moisture content of barley, and wheat grains respectively. The area based on arithmetic and geometric mean diameter increases from 4.02 to $4.69 \mathrm{~mm}^{2}$, and 3.26 to $3.93 \mathrm{~mm}^{2}$ for barley grains respectively, and 3.11 to $3.62 \mathrm{~mm}^{2}$ and 2.93 to $3.42 \mathrm{~mm}^{2}$ for wheat grains respectively. The volume of seeds also increased from 37.44 to $65.68 \mathrm{~mm}^{3}$ and 27.31 to $43.28 \mathrm{~mm}^{3}$ for barley and wheat seeds respectively, that showed similar trends were obtained for paddy and barley seeds [15, 27].

\subsubsection{Sphericity (Sp)}

The sphericity of barley and wheat seed increased with the increment of moisture content. The sphericity of barley and wheat seeds increased linearly from $42 \%$ to $45 \%$ and $62.5 \%$ to $63.5 \%$ for barley and wheat seeds respectively, as the moisture content increased from $14 \%$ to $22 \%$. Sphericity values of most agricultural products have been reported to range between 0.32 and 1.00 [16]. This also is a similar trend obtained in barley, cowpea, and paddy grains [1, 9, 28]. This suggests that as the grain's moisture content increases, its shape approaches to sphere shape. This is due to the differential dimensional changes of the three major dimensions as the grain absorbs moisture. The effect of moisture content on the sphericity was significant at a $5 \%$ probability level [15].

\subsubsection{Thousand Grain Mass}

The average thousand grain mass of barley, wheat, and tef grains were increased with the increment of moisture content. The average 1000 grain mass of barley seeds increased from $31.00 \mathrm{~g}$ at $14 \%$ to $34.50 \mathrm{~g}$ at $22 \%$, that of wheat seeds increased from $33.00 \mathrm{~g}$ at $14 \%$ to $37.50 \mathrm{~g}$ at $22 \%$ and tef seeds increased from $0.28 \mathrm{~g}$ at $14 \%$ to $0.39 \mathrm{~g}$ at $22 \%$ of moisture content (w.b.). This experiment was replicated three times to get a mean accuracy of the grain mass. This behavior occurs as a result of increased moisture content, which increases in size [9]. The outcomes are consistently obtained in lablab, wheat, cowpea, and barley seeds [15]. The individual seed mass of barley and wheat seeds also increased due to moisture content from $0.03 \mathrm{~g}$ to $0.04 \mathrm{~g}$ of each grain but the individual mass of tef grain was not measured due to the small size of tef grain that needs advanced measuring method.

\subsubsection{Surface Area}

The surface area of barley and wheat seeds was increased with an increase in moisture content. The surface area of barley and wheat grain increased linearly from 25.46 to $33.33 \mathrm{~mm}^{2}$ and 14.65 to $20.19 \mathrm{~mm}^{2}$ when the moisture content increased from 14 to $22 \% w . b$. in each grain as similar trends were reported in cowpea and lablab seeds [1, 23]. The rate of heat transfer to the material was significantly dependent on the surface area of seeds. The smaller the volume of material per unit surface, the better its condition for rapid heat transfer.

\subsubsection{Density}

\section{A. Bulk density}

The grains bulk density at different moisture levels varied from $497.83 \mathrm{~kg} / \mathrm{m}^{3}$ to $444.14 \mathrm{~kg} / \mathrm{m}^{3}$ and $932.50 \mathrm{~kg} / \mathrm{m}^{3}$ to $887.64 \mathrm{~kg} / \mathrm{m}^{3}$ for barley and wheat grains respectively. This indicates a decrease in bulk density was increasing in moisture content from 14 to $22 \%$ wet base. The negative relationship of bulk density with moisture content was also observed by various other research works in barley, cowpea, and wheat grains respectively $[1,15,18]$. This decreasing relation is because of an increase in mass owing to the moisture of again in the grain sample was lower than the accompanying volumetric expansion of the bulk [11]. Therefore, the volume of grains was more highly expanded than its mass possessing of water. Hence, the bulk density of grains was decreased due to the expansion of its volume.

B. True density

The true density of barley and wheat grains at different moisture content was varied from $934.95 \mathrm{~kg} / \mathrm{m}^{3}$ to $776.52 \mathrm{~kg} / \mathrm{m}^{3}$ and $1391.89 \mathrm{~kg} / \mathrm{m}^{3}$ to $1201.51 \mathrm{~kg} / \mathrm{m}^{3}$ respectively. An increase in moisture showed that a decrease in the true density of the crops. The result is similarly obtained in barley, cowpea, and wheat grains $[1,11,15]$. The decrease in the true density was mainly due to the larger increase in grains volume compared to the increase in grains mass.

\subsubsection{Porosity}

The porosity (percent of pore space between the grains) was calculated by using the data presented on the bulk and true densities of the barley, and wheat grains. The porosity of barley and wheat grain decreased linearly from 46.75 to $42.80 \%$ and 33.01 to $26.12 \%$, with increasing moisture content from 14 to $22 \%$ respectively. This difference between the two crops could be due to the cell structure, volume, and also mass increase characteristics of the samples, as the moisture content of grains increases. The reason is the decreasing porosity of barley and wheat gains when the grain becomes more moisture and their volume increased more than its mass thus, the number of grains in a fixed volume decreased. Since the number of grains per unit volume decreases, the value of porosity also decreases. The outcomes are consistent with the outcome that was obtained in barley, lablab, wheat, cowpea, and barley seeds that affect packing and resistance to airflow through bulk seeds $[1,11,18,19$, 23].

\subsubsection{Angle of Repose}

The measured average value of the angle of repose was increased from $28.50^{\circ}$ to $37.85^{\circ}, 25.75^{\circ}$ to $34.15^{\circ}$, and $35.20^{\circ}$ to $40.25^{\circ}$ for barley, wheat, and tef grain respectively as the moisture content increased from (14 to 22$) \%$ wet bases. This 
increasing trend of the angle of repose with moisture content occurs because the surface layer of moisture surrounding the particle holds the aggregate of grain together by the surface tension [27]. These results were also reported in barley, soybean, and maize, and cereal and oilseeds [15, 24, 26]. The particle holds the aggregate of grain together by the surface in tension. It is also an important factor for designing the equipment of mass flow and storage structures.

\subsubsection{Coefficient of Friction}

The coefficient of friction of materials on various structural surfaces is important in predicting the movement of the materials in handling and harvesting equipment and the pressure exerted on the walls of the storage structures. The static coefficient of frictions of the grains on the surfaces of plywood and iron sheet metal was increased with moisture content in the moisture range of $14 \%$ to $22 \%$ (w.b.) for barley, wheat, and tef seeds respectively. It was observed that the static coefficient of friction increased linearly from 36.10 to $62.85 \%, 35.41$ to $60.92 \%$, and 44.94 to $67.91 \%$ of barley, wheat, and tef grains respectively, with moisture content, increased from 14 to $22 \%$ wet base. The reason for the increased friction coefficient at higher moisture content was owing to the water present in the grain which offers a cohesive force on the surface of contact. As the moisture content of grains increases, the surface of the samples becomes stickier. Water tends to adhere to surfaces and the water on the moist seed surface would be attracted to the surface across which the sample is being moved [28]. It was similar trends obtained in wheat, and cereal, and oilseeds respectively. The coefficient of friction increased with increasing moisture content in each grain [18, 24, 26].

\subsection{Performance of Thresher}

The performance evaluation of the thresher was determined by threshing capacity, threshing efficiency, cleaning efficiency, fuel consumption, and percentage of harvesting loss.

\subsubsection{Threshing Capacity (Tc)}

Threshing capacity was highly influenced by the moisture content of barley, wheat, and tef crop biomass. The mean with a standard error of threshing capacity and analysis of variance were presented in Table 1 for all grains. The ANOVA indicated that the threshing capacity of multi-crop thresher made in MARC was significantly affected by the moisture content of barley, wheat, and tef crop biomass at ( $\mathrm{P}$ $<0.05)$. The maximum threshing capacity $(\mathrm{Kg} / \mathrm{hr}$.) was $651.66,392.66$, and 418.69 observed at $14 \%$ moisture content; whereas the minimum threshing capacity was 383.36 , 327.00, and 325.98 for barley, wheat, and tef grains respectively when the moisture content was $22 \%$. This indicates that when the moisture content of the crop increased the threshing capacity $(\mathrm{kg} / \mathrm{hr}$.) of the machine was decreased because the moisture content of the crop affects the performance of the thresher. This result is the same trend as reported in wheat grains [30]. The regression analysis was made to establish a relationship between the moisture content of the crop biomass, and the performance of the thresher $(\mathrm{kg} / \mathrm{hr}$.). A regression question was made for their relationships between the threshing capacity (Tc) and the moisture content $(\mathrm{M})$ of barley, wheat, and tef grains can be represented by the following equations:

$$
\begin{gathered}
\mathrm{Tc}=-33.5371 \mathrm{M}+1102.73, \mathrm{R}^{2}=0.77 \text { for barley } \\
\mathrm{Tc}=-8.20719 \mathrm{M}+507.284, \mathrm{R}^{2}=0.45 \text { for wheat } \\
\mathrm{Tc}=-11.5878 \mathrm{M}+587.163, \mathrm{R}^{2}=0.66 \text { for } \text { tef }
\end{gathered}
$$

The regression equation shows that the moisture content of crops has a negative impact on threshing capacity with a strong correlation of $\mathrm{R}^{2}=0.77$, an intermediate correlation of $\mathrm{R}^{2}=0.66$ and a medium correlation of $\mathrm{R}^{2}=0.45$ for barley, wheat, and tef grains respectively.

Table 1. Effects of moisture content on the threshing capacity of barley, wheat, and tef seeds.

\begin{tabular}{llll}
\hline \multicolumn{4}{l}{ Threshing capacity (kg/hr.) crops } \\
\hline $\begin{array}{l}\text { Moisture } \\
\text { content (\%) }\end{array}$ & Barley & Wheat & Tef \\
\hline 14 & $651.66^{\mathrm{A}} \pm 37.814$ & $392.66^{\mathrm{A}} \pm 20.049$ & $418.69^{\mathrm{A}} \pm 10.318$ \\
18 & $462.18^{\mathrm{B}} \pm 23.762$ & $359.00^{\mathrm{AB}} \pm 11.837$ & $391.08^{\mathrm{A}} \pm 18.347$ \\
22 & $383.36^{\mathrm{B}} \pm 31.133$ & $327.00^{\mathrm{B}} \pm 18.533$ & $325.98^{\mathrm{B}} \pm 14.366$ \\
Mean & $499.06 \pm 37.709$ & $359.56 \pm 12.076$ & $378.58 \pm 14.012$ \\
SE (\%) & 44.450 & 24.297 & 20.808 \\
LSD & 100.55 & 54.964 & 47.071 \\
CV (\%) & 12.60 & 9.56 & 7.77 \\
\hline
\end{tabular}

SED: Standard errors of differences of means; LSD: Least significance difference; CV: Coefficient of variation; Means followed by the same letters are not significantly different at $5 \%$ level of probability.

\subsubsection{Threshing Efficiency $\left(\eta_{t}\right)$}

The threshing efficiency (\%) of the machine was highly influenced by the moisture content of barley, wheat, and tef crop biomass. The mean with a standard error of threshing efficiency and analysis of variance were presented in Table 2 of each grain. The ANOVA indicated that the threshing efficiency of multi-crop thresher made in MARC was significantly affected by the amount of moisture content of barley, wheat, and tef biomass at $(\mathrm{P}<0.05)$. The maximum threshing efficiency (\%) of the thresher was 97.629, 97.682, and 97.740 , observed at $14 \%$ moisture content; whereas the minimum threshing efficiency of the machine was 95.091 , 95.560 , and 95.543 observed at the moisture content of $22 \%$ for barley, wheat, and tef crop threshing respectively. This indicates that when the moisture content increased, the threshing efficiency (\%) of the machine was decreased because the amount of moisture content presented on the crop affects the performance of the thresher that results in line with other findings [20]. The regression analysis was made to establish a relationship between the moisture content of the crop biomass and the performance of the thresher in $(\%)$. From regression coefficients their relationships between the threshing efficiency $\left(\mathrm{n}_{\mathrm{t}}\right)$ and the moisture content $(M)$ of barley, wheat, and tef grains can be represented by the following equations; 


$$
\begin{array}{r}
\left(\eta_{\mathrm{t}}\right)=-0.31737 \mathrm{M}+102.064, \mathrm{R}^{2}=0.58 \text { barley } \\
\left(\eta_{\mathrm{t}}\right)=-0.26531 \mathrm{M}+101.383, \mathrm{R}^{2}=0.64 \text { wheat } \\
\left(\eta_{\mathrm{t}}\right)=-0.27469 \mathrm{M}+101.650, \mathrm{R}^{2}=0.68 \text { tef }
\end{array}
$$

The equation shows that the threshing efficiency had a negative relationship with the moisture content with an intermediate correlation of $\mathrm{R}^{2}=0.58,0.64$, and 0.68 for barley, wheat, and tef seeds respectively.

Table 2. Effects of moisture content on threshing efficiency of barley, wheat, and tef seeds.

\begin{tabular}{llll}
\hline \multicolumn{3}{l}{ Threshing efficiency (\%) crops } \\
\hline $\begin{array}{l}\text { Moisture } \\
\text { content (\%) }\end{array}$ & Barley & Wheat & Tef \\
\hline 14 & $97.629^{\mathrm{A}} \pm 0.1060$ & $97.682^{\mathrm{A}} \pm 0.0774$ & $97.740^{\mathrm{A}} \pm 0.2231$ \\
18 & $96.334^{\mathrm{AB}} \pm 0.4603$ & $96.580^{\mathrm{AB}} \pm 0.3446$ & $96.833^{\mathrm{A}} \pm 0.5015$ \\
22 & $95.091^{\mathrm{B}} \pm 0.7370$ & $95.560^{\mathrm{B}} \pm 0.5520$ & $95.543^{\mathrm{B}} \pm 0.2796$ \\
Mean & $96.351 \pm 0.4091$ & $96.608 \pm 0.3276$ & $96.706 \pm 0.3292$ \\
SE (\%) & 0.7147 & 0.5350 & 0.5029 \\
LSD & 1.6169 & 1.2103 & 1.1377 \\
CV (\%) & 1.0500 & 0.7800 & 0.7400 \\
\hline
\end{tabular}

SED: Standard errors of differences of means; LSD: Least significance difference; CV: Coefficient of variation; Means followed by the same letters are not significantly different at $5 \%$ level of probability.

\subsubsection{Cleaning Efficiency (n)}

The cleaning efficiency of the thresher was highly influenced by the moisture content of barley, wheat, and tef crop in biomass. The mean with a standard error of cleaning efficiency and analysis of variance were presented in Table 3. The ANOVA indicated that the cleaning efficiency of multicrop thresher made in MARC was significantly affected by the amount of moisture content of barley, wheat, and tef crops at $(\mathrm{P}<0.05)$. The maximum cleaning efficiency $(\%)$ of the crops was $94.824,88.335$, and 88.604 , observed at $14 \%$ moisture content; whereas the minimum cleaning efficiency was $89.246,69.368$, and 75.633 observed at the moisture content of $22 \%$ barley, wheat, and tef crop biomass.

In general, the cleaning efficiency $(\%)$ of the machine increased with a decrease in moisture content, while it declined with the increased moisture content of crops because the amount of moisture content presented on the crop affects the performance of the thresher. This means that increased moisture content gave less cleaning efficiency due to the presence of high amounts of impurity or chaff which causes the clogging effect of chaffs on the wall of the concave and drums of the thresher and also on the sieve screens, which also reported through other results [19].

The regression analysis was made to establish a relationship between the moisture content of the crop biomass and the performance of the thresher in (\%). From regression coefficients their relationships between the cleaning efficiency $\left(\eta_{c}\right)$ and the moisture content $(M)$ of barley, wheat, and tef grains can be represented through the following equations;

$$
\begin{aligned}
& \left(\eta_{c}\right)=-0.69731 M+104.238 R^{2}=0.75 \text { barley } \\
& \left(\eta_{c}\right)=-2.37094 M+121.939 R^{2}=0.94 \text { wheat }
\end{aligned}
$$

$$
\left(n_{c}\right)=-1.62141 M+110.755 R^{2}=0.76 \text { tef }
$$

The regression equation above showed that the cleaning efficiency of the machine had an indirect (negative) relationship with the moisture content of crops. Therefore, when the moisture content of the crop increased, the cleaning efficiency of the thresher was decreased with a strong correlation of $\mathrm{R}^{2}=0.75,0.94$, and 0.76 for barley, wheat, and tef grains respectively.

Table 3. Effects of moisture content on cleaning efficiency of barley, wheat, and tef seeds.

\begin{tabular}{llll}
\hline \multicolumn{3}{l}{ Cleaning efficiency (\%) crops } & \\
\hline $\begin{array}{l}\text { Moisture } \\
\text { content (\%) }\end{array}$ & Barley & Wheat & Tef \\
\hline 14 & $94.824^{\mathrm{A}} \pm 0.8357$ & $88.335^{\mathrm{A}} \pm 1.2796$ & $88.604^{\mathrm{A}} \pm 1.9378$ \\
18 & $90.989^{\mathrm{B}} \pm 0.7098$ & $80.082^{\mathrm{B}} \pm 1.0854$ & $80.471^{\mathrm{B}} \pm 1.5084$ \\
22 & $89.246^{\mathrm{B}} \pm 0.5032$ & $69.368^{\mathrm{C}} \pm 0.8449$ & $75.633^{\mathrm{B}} \pm 1.4694$ \\
Mean & $91.686 \pm 0.7911$ & $79.262 \pm 2.4088$ & $81.569 \pm 1.8299$ \\
SE (\%) & 0.9851 & 1.5339 & 2.3366 \\
LSD & 2.2284 & 3.4698 & 5.2858 \\
CV (\%) & 1.5200 & 2.7400 & 4.0500 \\
\hline
\end{tabular}

SED: Standard errors of differences of means; LSD: Least significance difference; CV: Coefficient of variation; Means followed by the same letters are not significantly different at $5 \%$ level of probability.

\subsubsection{Germination Rate}

Germination rate was highly influenced by the moisture content of barley, wheat, and tef crop biomass. The mean with a standard error of the rate of germination and analysis of variance were presented in Table 4. The ANOVA table indicated that the rate of germination was significantly affected by the moisture content of crop biomass at $(\mathrm{P}<0.05)$. The maximum germination rate (\%) of the crop was 94.255 , 95.360, and 95.854, observed at $14 \%$ moisture content; whereas the minimum rate of germination was 90.109, 89.763 , and 89.605 at the moisture content of $22 \%$ for barley, wheat, and tef grains respectively. This is the same result obtained by other scholars [10]. It indicates that when the moisture content of grains increased the rate of germination decreased because the highest moisture content of grain affects the rate of transpiration of seeds.

The regression analysis was made to establish a relationship between the moisture content of the biomass and the germination rate $(\%)$. From regression coefficients, their relationships between the rate of germination $(\mathrm{G})$ and the moisture content $(\mathrm{M})$ of barley, wheat, and tef grains can be represented by the following equations.

$$
\begin{gathered}
\mathrm{G}=-0.51822 \mathrm{M}+101.645 \mathrm{R}^{2}=0.62 \text { barley } \\
\mathrm{G}=-0.69969 \mathrm{M}+105.165 \mathrm{R}^{2}=0.79 \text { wheat } \\
\mathrm{G}=-0.78105 \mathrm{M}+107.356 \mathrm{R}^{2}=0.84 \text { tef }
\end{gathered}
$$

The regression equation above shows that the rate of germination of the seeds had a negative relationship with moisture content. Therefore, when the moisture content of the crop increased, the rate of germination of the seed was decreased with an intermediate correlation $R^{2}=0.62$ of barley 
and a strong correlation of $\mathrm{R}^{2}=0.79$ and 0.84 for wheat and tef respectively.

Table 4. The germination rate of barley, wheat, and tef crops at different moisture content.

\begin{tabular}{llll}
\hline \multicolumn{4}{l}{ Germination rate (\%) of crops } \\
\hline $\begin{array}{l}\text { Moisture } \\
\text { content (\%) }\end{array}$ & Barley & Wheat & Tef \\
\hline 14 & $94.255^{\mathrm{A}} \pm 0.3990$ & $95.360^{\mathrm{A}} \pm 0.3817$ & $95.854^{\mathrm{A}} \pm 0.3266$ \\
18 & $92.586^{\mathrm{A}} \pm 0.3108$ & $92.590^{\mathrm{B}} \pm 0.2796$ & $94.431^{\mathrm{B}} \pm 0.3773$ \\
22 & $90.109^{\mathrm{B}} \pm 1.2015$ & $89.763^{\mathrm{C}} \pm 1.0848$ & $89.605^{\mathrm{C}} \pm 0.5567$ \\
Mean & $92.317 \pm 0.6467$ & $92.571 \pm 0.7759$ & $93.297 \pm 0.8372$ \\
SE (\%) & 1.0644 & 0.9663 & 0.6104 \\
LSD & 2.4078 & 2.1860 & 1.3808 \\
CV (\%) & 1.63 & 1.48 & 0.93 \\
\hline
\end{tabular}

SED: Standard errors of differences of means; LSD: Least significance difference; $\mathrm{CV}$ : Coefficient of variation; Means followed by the same letters are not significantly different at $5 \%$ level of probability.

\subsubsection{Fuel Consumption (fc)}

Fuel consumption was highly influenced by the moisture content of barley, wheat, and tef crops in biomass. The mean with a standard error of fuel consumption and analysis of variance are presented in Table 5. It shows that the fuel consumption, in $\mathrm{L} / \mathrm{hr}$.,), of the machine when operated at different moisture contents, and the ANOVA table indicated that the fuel consumption of multi-crop thresher made in MARC was significantly affected by the amount of moisture content of barley, wheat, and tef biomass at $(\mathrm{P}<0.05)$. The maximum fuel consumption (L/hr.) was 2.0213, 2.7300, and 2.3560 , observed at $22 \%$ moisture content; whereas the minimum fuel consumption was 1.1650, 1.7200, and 1.6960, at the moisture content of $14 \%$. Furthermore, the fuel consumption of the system was increasing sharply from 1.14 $\mathrm{l} / \mathrm{hr}$. to $2.02 \mathrm{l} / \mathrm{hr}$., $1.72 \mathrm{l} / \mathrm{hr}$. to $2.73 \mathrm{l} / \mathrm{hr}$, and $1.70 \mathrm{l} / \mathrm{hr}$. to 2.36 $1 / \mathrm{hr}$. at which the moisture content of the barley, wheat, and tef crop biomass was increased from $14 \%$ to $22 \%$ respectively. This indicates that at $22 \%$ moisture content the energy required to thresh the crop biomass was high. Therefore, the fuel consumption needed in this moisture content as high as obtained in other reports [30]. In general, the fuel consumption of the machine increased when, the moisture content of barley, wheat, and tef crop biomass was increased. As shown in Table 5 , fuel consumption increased with an increased moisture content of crops during threshing operation.

The regression analysis was made to establish a relationship between the moisture content of the biomass and fuel consumption $(1 / \mathrm{hr}$.). From regression coefficients, their relationships between the fuel consumption $(\mathrm{Fc})$ and the moisture content $(\mathrm{M})$ of barley, wheat, and tef grains can be represented by the following equations.

$$
\begin{aligned}
& F(c)=0.11059 \mathrm{M}-0.40927 \mathrm{R}^{2}=0.94 \text { barley } \\
& F(\mathrm{c})=0.12625 \mathrm{M}-0.06083 \mathrm{R}^{2}=0.80 \text { wheat } \\
& \mathrm{F}(\mathrm{c})=0.08250 \mathrm{M}-0.5405 \mathrm{R}^{2}=0.77 \text { tef }
\end{aligned}
$$

Based on the regression coefficients, the moisture contents were found to be, the greater contribution to fuel consumption as indicated in the equation above. Moisture contents have a direct relationship to fuel consumption at a strong correlation of $\mathrm{R}^{2}=0.94,0.80$, and 0.77 for barley, wheat, and tef seeds respectively.

Table 5. Fuel consumption of barley, wheat, and tef crops at different moisture content.

\begin{tabular}{llll}
\hline \multicolumn{4}{l}{ Fuel consumption (l/hr) crops } \\
$\begin{array}{l}\text { Moisture } \\
\text { content (\%) }\end{array}$ & Barley & Wheat & Tef \\
\hline 14 & $1.1365^{\mathrm{C} \pm} 0.0331$ & $1.7200^{\mathrm{C}} \pm 0.0726$ & $1.6960^{\mathrm{C}} \pm 0.0509$ \\
18 & $1.5865^{\mathrm{B} \pm} 0.0662$ & $2.1850^{\mathrm{B}} \pm 0.1809$ & $2.0248^{\mathrm{B}} \pm 0.0864$ \\
22 & $2.0213^{\mathrm{A} \pm} 0.0549$ & $2.730^{\mathrm{A}} \pm 0.0610$ & $2.3560^{\mathrm{A}} \pm 0.1069$ \\
Mean & $1.5814 \pm 0.1124$ & $2.2117 \pm 0.1388$ & $2.0256 \pm 0.0925$ \\
SE $(\%)$ & 0.0753 & 0.1667 & 0.1197 \\
LSD & 0.1703 & 0.377 & 0.2709 \\
CV $(\%)$ & 6.73 & 10.66 & 8.36 \\
\hline
\end{tabular}

SED: Standard errors of differences of means; LSD: Least significance difference; $\mathrm{CV}$ : Coefficient of variation; Means followed by the same letters are not significantly different at $5 \%$ level of probability.

\subsubsection{Threshing Loss}

The percentage of loss during threshing was highly influenced by the moisture content of barley and wheat crops in biomass. The ANOVA, on the threshing data of the thresher, revealed that the moisture content of crops had highly significant effects on the grain breakage of the machine. ANOVA was presented in Table 6. It indicated that the grain threshing loss of multi-crop thresher made in MARC was significantly affected by the moisture content of barley and wheat crops at $(\mathrm{P}<0.05)$. The maximum quantity of grain loss to the total quantity of the crop yield during threshing of grain (\%) was 2.8655 and $2.6375 \%$, observed at $14 \%$ moisture content while the minimum threshing loss (\%) was 1.6300 and $1.3750 \%$ observed when the moisture content was $22 \%$ for barley, wheat, and tef crop respectively. It also showed that the grain loss was decreased at which the moisture content of crops increased as supported by similar findings in corn and wheat grains [3, 14]. But the breakage of tef grain was not identified (difficult to determined) because the size of the tef grain is very small, which needs an advanced measuring instrument. In general, the grain loss of the machine was decreased while, increasing the moisture content of crops. As shown in Table 6, the threshing loss of grain decreases with an increased moisture content of crops during threshing operation. The regression analysis was made to establish a relationship between the moisture content of the crop biomass and the breakage of grains (\%). From regression coefficients, their relationships between the grain breakage $(\mathrm{Gb})$ and the moisture content (M) of barley, wheat, and tef grains can be represented by the following equations.

$$
\begin{gathered}
\mathrm{Gb}=-0.15444 \mathrm{M}+5.02421 \mathrm{R}^{2}=0.60 \text { barley } \\
\mathrm{Gb}=-0.15781 \mathrm{M}+4.83646 \mathrm{R}^{2}=0.78 \text { wheat }
\end{gathered}
$$

The regression equation above shows that the moisture content of crops is a negative impact on the contribution of a percentage of grain breakage at an intermediate correlation of $\mathrm{R}^{2}=0.60$ for 
barley and a strong correlation of $\mathrm{R}^{2}=0.78$ for wheat seeds.

Table 6. Grain breakage of barley and wheat crops at the different moisture content.

\begin{tabular}{lll}
\hline Grain breakage (\%) crops & \\
\hline Moisture content (\%) & Barley & Wheat \\
\hline 14 & $2.8655^{\mathrm{A}} \pm 0.3414$ & $2.6375^{\mathrm{A}} \pm 0.1055$ \\
18 & $2.2375^{\mathrm{AB}} \pm 0.2172$ & $1.9750^{\mathrm{B}} \pm 0.1841$ \\
22 & $1.6300^{\mathrm{B}} \pm 0.0902$ & $1.3750^{\mathrm{C}} \pm 0.1684$ \\
Mean & $2.2443 \pm 0.1969$ & $1.9958 \pm 0.1756$ \\
SE (\%) & 0.3385 & 0.2212 \\
LSD & 0.7658 & 0.5003 \\
CV $(\%)$ & 21.3300 & 15.67 \\
\hline
\end{tabular}

SED: Standard errors of differences of means; LSD: Least significance difference; CV: Coefficient of variation; Means followed by the same letters are not significantly different at $5 \%$ level of probability.

\section{Conclusion and Recommendation}

\subsection{Conclusion}

This study concluded that wide variation exists among the barley and wheat grain dimensions concerning the physical properties determined. The linear dimensions (length, width, and thickness) and also arithmetic mean diameter, geometric mean diameter, equivalent mean diameter, surface area, sphericity, coefficient of friction, thousand-grain mass, fuel consumption, and angle of repose were linearly increased with increased grain moisture content at a range of 14 to $22 \%$ w.b. While bulk and true (particle) density, breakage of grain, threshing capacity, threshing efficiency, porosity, percentage of blower losses, and cleaning efficiency of the barley (HB 42 variety), wheat (Kakaba variety), and teff (Magna variety) were decreased with increasing of moisture content. This indicates that moisture content is the most important factor to determine the grain's physical property. In this study (14-18) \% moisture content was suggested as the threshing capacity, threshing efficiency, and cleaning efficiency were gives better results compared to the other moisture levels, and also had least fuel consumptions.

\subsection{Recommendation}

The performance evaluation result obtained from Melkassa-made multi-crop thresher was recommended that:

1. Once the plants are cut, they are left in the ground of a small heap in the field for further drying. This causes losses of grains during drying.

2. To reduces this problem appropriate harvesting moisture content is required.

3. This study recommends that the harvesting and threshing moisture content of most cereal crops be laid between $14-18 \%$

\section{References}

[1] Aderinlewo, A. A., Raji, A. O., and Olayanju, T. M. A. (2011). Effect of moisture content on some physical properties of cowpea (Vigna Unguiculata). Journal of Natural Sciences, Engineering, and Technology, 10 (2), 133-145.
[2] Adinoyi, A., Ajeigbe, H. A., Angarawai, I. I., and Kunihya, A. (2017). Effect of grain moisture content on the physical properties of some selected sorghum varieties. International Journal of Scientific and Engineering Research, 8 (6), 17961805.

[3] Al Sharifi, S. K. A., Aljibouri, M. A., and Taher, M. A. (2019) Effect of threshing machines, rotational speed, and grain moisture on corn shelling. Bulgarian Journal of Agricultural Science, 25 (2), 243-255.

[4] Alemayehu Refera, A. (2001). TEF: Post-harvest operations. Addis Ababa, Ethiopia: Institute of Agricultural Research Organization, Holeta Agricultural Research Center (IARO).

[5] Hagberg, M., and Wegman, D. H. (1987). Prevalence rates and odds ratios of shoulder-neck diseases in different occupational groups. Occupational and environmental medicine, 44 (9), 602-610.

[6] Hailu Gebreand van Leur, J. A. G. (1993). Barley's research in Ethiopia: past work and prospects. In Proceedings of the 1st Barley Research Review Workshop (pp. 16-19).

[7] Hamada, E., Ghini, R., Fernandes, J. L., Júnior, P., José, M., and Rossi, P. (2008). Spatial and temporal variability of leaf wetness duration in the State of São Paulo, Brazil. Scientia Agricola, 65: 26-31.

[8] Ioannis, S. A., and Persefoni, T. (2008). Cereal waste management: Treatment methods and potential uses of treated waste. Waste Management for the Food Industries, 629-702.

[9] Irtwange, S. V., and Igbeka, J. C. (2002). Some physical properties of two African yam bean (Sphenostylis stenocardia) accessions and their interrelations with moisture content. Applied Engineering in Agriculture, 18 (5), 567.

[10] Hanumantharaju K. N., Vikas L, and Mr. Prassana Kumar. (2017). Comparison study of prototype thresher with different methods of threshing whole crop finger millet. International Journal of Science, Environment, and Technology, 391-398.

[11] Karimi, M., Kheiralipour, K., Tabatabaeefar, A., Khoubakht, G. M., Naderi, M., and Heidarbeigi, K. (2009). The effect of moisture content on the physical properties of wheat. Pakistan Journal of Nutrition, 8 (1), 90-95.

[12] Kumar, P., Yadava, R. K., Gollen, B., Kumar, S., Verma, R. K., and Yadav, S. (2011). Nutritional contents and medicinal properties of wheat: a review. Life Sciences and Medicine Research, 22, 1-10.

[13] Lovis, L. J. (2003). Alternatives to wheat flour in baked goods. Cereal Foods World, 48 (2), 61.

[14] Lupu, C. M. Canja V, and Pădureanu (2014). The analysis of the cereal grains' mechanical properties. International Journal of Engineering and Management in Food and Tourism 1 (16). 280-283.

[15] Mahmoud Tavakoli, Hamed Tavakoli, Ali Rajabipour, Hojat Ahmadi. (2009). Moisture-dependent physical properties of barley grains. Food Science, and Technology.

[16] Mohsenin, N. N. (1970). Physical properties of the plant and animal materials. Vol. 1. Structure, physical characteristics, and mechanical properties. Physical properties of the plant and animal materials. Vol. 1. Structure, physical characteristics, and mechanical properties, 1 . 
[17] Mohsenin, N. N. (1986). Physical properties of plant and animal materials (No. 581.1 M64 1986).

[18] Öztürk T. and Esen B. (2008). Physical and mechanical properties of barley. Agricultural Tropica et Sub tropica, 117121.

[19] Patricia Arguedas Gamboa, (2008). TEF "Survey on the nutrition)", Instituto Tecnológico de Costa Rica, Sede Central. al and health aspects of tef (Eragrostis Tef).

[20] Salih K. Alwan A Sharifi, Mousa A. Aljibouri, Manhil Abass Taher. (2019). Affecting on threshing machine types, grain moisture content, and cylinder speeds for maize, Cadiz variety. Agricultural Engineering International, CIGR, 20 (3), 233244.

[21] Shewry, P. R. (2007). Improving the protein content and composition of cereal grain. Journal of cereal science, 46 (3), 239-250.

[22] Shewry, P. R. (2009). The HEALTH GRAIN program opens new opportunities for improving wheat for nutrition and health. Nutrition Bulletin, 34 (2), 225-231.

[23] Simonyan, K. J., Yiljep, Y. D., Oyatoyan, O. B., and Bawa, G. S. (2009). Effects of moisture content on some physical properties of Lablab purpureus (L.) sweet seeds. Agricultural Engineering International: CIGR Journal.

[24] Soyoye, B. O., O. C. Ademosun, and L. A. S. Agbetoye. (2018). Determination of some physical and mechanical properties of soybean and maize about planter design. Agricultural Engineering International: CIGR Journal, 20 (1): 81-89.
[25] Tabatabaeefar, A. (2003). Moisture-dependent physical properties of wheat. International Agrophysics, 17 (4), 207212.

[26] Muir W. E. And R. N. Sinha. (1987). Physical properties of cereal and oilseed cultivars grown in western Canada. Canadian Agricultural Engineering, 51-55.

[27] Zareiforoush, H. (2009). Effect of moisture content on some physical properties of paddy grains. Research Journal of Applied Sciences, Engineering, and Technology, 1 (3), 132139.

[28] Zareiforoush, H., Komarizadeh, M. H., and Alizadeh, M. R. (2010). Effects of crop-machine variables on paddy grain damage during handling with an inclined screw auger. Biosystems Engineering, 106 (3), 234-242.

[29] Gomez, A. K., and Gomez, A. A. (1984). Statistical Procedures for Agricultural Research 2nd edition. John Wiley and Sons, New York, p. 97-107.

[30] Ahmad, S.; Ahsan-ul-Haq; Yousaf, M.; Kamran, Z.; Ata-urRehman; Sohail, M. U.; Shahid-ur-Rahman, 2013. Effect of feeding the whole linseed as a source of polyunsaturated fatty acids on performance and egg characteristics of laying hens kept at high ambient temperature. Braz. J. Poult. Sci., 15 (1): 21-25.

[31] Alemayehu Seyoum Taffesse, Paul Dorosh, and Sinafikeh Asrat. 2011. Development Strategy and Governance Division, International Food Policy Research Institute, Ethiopia Strategy Support Program II, Ethiopia. Ethiopia Strategy Support Program II (ESSP II), ESSP II Working Paper No. 0016. 